\title{
O GUERREIRO DE FRONTEIRA BIZANTINO AKRITES SEGUNDO O STRATEGIKON DE CECAUMENOS (SÉCULO $\mathrm{XI})$
}

\author{
João Vicente de Medeiros Publio Dias ${ }^{1}$
}

Uma das características principais do geist bizantino é seu conservadorismo. Esse pode ser observado em várias facetas: na religião, na política e na cultura, apesar de Alexander Kahzdan e Ann Eppstein proporem que, nos séculos XI e XII, houve um afrouxamento no conservadorismo nessas duas áreas. ${ }^{2}$ Contudo, tinha seus limites, pois se a concepção de mundo dessa civilização fosse totalmente intransigente, Bizâncio não duraria o milênio que durou, e isso é visível na sua organização política.

A Restauratio Imperii empreendida por Justiniano I (527565) reconquista, recolocando sob a autoridade do Imperador Romano, porém agora em Constantinopla, as regiões do Norte de África, parte da Itália, incluindo Roma, e o sul da Península Ibérica. A Restauratio será mantida, e até expandida, posteriormente até o governo de Heráclio I (610-641). Porém, nem o Império, que não tinha mais a capacidade de manter províncias tão longínquas, nem a região Mediterrânica, nesse momento politicamente dividida pelos reinos germânicos (francos, ostrogodos, visigodos), nascidos sobre os escombros da pars ocidentalis do Império Romano, era a mesma da época do Principado fundado por Augusto. Desse modo, a reconquista justiniana se revelou frágil, impossível de se manter, pois gradativamente esses territórios foram perdidos ou abandonados, e de certa forma nociva. A obsessão de Justiniano pela reconquista do ocidente o fez dar as costas às províncias orientais, resultando que o principal adversário do Império Bizantino nessa época, o Império

\footnotetext{
${ }^{1}$ Mestrando em História pela UFPR

${ }^{2}$ KAZHDAN. A. P. \& EPSTEIN, Ann Wharton. Change in Byzantine Culture in the Eleventh and Twelfht Centuries. Berkeley: University of California Press. 1985.
} 
Persa Sassânida, se aproveitasse da situação e ocupasse muitas das províncias bizantinas orientais. Esse avanço significativo fez o Imperador Heráclio I agir. Gradativamente as forças imperiais bizantinas entraram em território persa, porém não conquistaram a capital sassânida Ctesifonte e ganharam de uma vez por todas um conflito que já durava séculos e havia virado uma obsessão dos Imperadores Romanos e Bizantinos.

Apesar do resultado, ambos os lados saíram extremamente fragilizados, criando assim um ambiente propício para a chegada de um novo povo conquistador, vindo dos desertos arábicos e movidos por uma nova fé: os muçulmanos. A primeira grande conquista do Islã foi o derrotado, por isso enfraquecido, Império Sassânida. Apesar de seu desaparecimento, muito de sua cultura e sociedade foram mantidas pelos muçulmanos e que agora formavam um enorme Império sob a liderança do Califa, o sucessor do profeta. Conseqüentemente, o Califado, ao substituir o Império Persa, se viu diante do maior inimigo de seus conquistados, Império Bizantino, que estava também bastante debilitado pelo custo do longo conflito, e dividido internamente por querelas teológicas. Devido esses fatores, o Califado não teve muitas dificuldades em conquistar as províncias romanas da Palestina, Síria, Egito e Norte da África, províncias de maioria étnica árabe-semítica e religiosa cristã monofisita, um credo diferente do oficial niceno, e que sofriam constante pressão do governo imperial, devido à urgência de unidade religiosa que existia na ideologia imperial bizantina. ${ }^{4}$

A resposta do poder imperial a esse novo contexto político foi a redisposição do Império Bizantino em Themas. Reorganização que vai abranger desde o redesenho das províncias, organização e

${ }^{3}$ TREADGOLD. Warren. A History of the Byzantine State and Society. Stanford, California: Stanford University Press. 1997. pp. 287-306 \& ARCE, Javier. La Frontera Del Império Persa: Constâncio II y Heráclio. Eryhteia: numero 8/1, Madrid: Asociación Hispano-Helenica. 1987.

${ }^{4}$ PATLAGEAN,E. et al. Historia de Bizâncio. Critica: Barcelona. 2001. pp. 68-77. 
mobilização militar, até os métodos de captação de impostos. ${ }^{5} \mathrm{O}$ sistema de Themas se origina, segundo John Haldon, das antigas forças orientais do tardio Império Romano, ou já Bizantino, que, a partir da década de 630 , com a conquista muçulmana de grande parte do Império, refugiaram-se na Ásia Menor. Dessa forma a região onde cada exército estava acampado se tornou um distrito, um thema, mas com uma denominação grega ao invés de latina. Assim as tropas do Magister Militum per Orientem originaram o Thema dos Anatolikon, o Magister Militum per Armeniam que veio a ser o Thema dos Armeniakon. A única exceção européia será o Magister Militum per Thracias, que se tornou o Thema de Thrakesion. ${ }^{6}$ Sua administração se inspirou nos exarcados criados pelos imperadores Maurício (582602) e Heráclio I (610-641), que combinavam o poder militar e o civil na mão de uma autoridade: o Exarca. ${ }^{7}$ No caso dos themas quem exercia esse poder civil e militar associado era o Strategos, "general" em grego. Cada thema devia sustentar um exército próprio, formado por um sistema que lembra bastante os antigos limitanei tardo-romanos, ou seja, pequenos proprietários rurais que em troca de isenções fiscais e pago anual deviam fornecer pelo menos um soldado a esses exércitos provinciais. Tal sistema era chamado de strateia e foi a pedra-angular da estabilidade do Império em períodos posteriores. Apesar de pequenas alterações, o sistema themático manteve-se basicamente inalterado até meados do século X. O sistema foi expandido por todo o Império, os distritos inicialmente extensos foram gradativamente subdivididos em unidades menores, $\mathrm{o}$ pago dos soldados thematicos foi dobrado pelo Imperador Teófilo (829-842), assim como o número de soldados que foi expandido no reinado desse mesmo imperador pela absorção de mais de 30.000

\footnotetext{
${ }^{5}$ Sobre a criação do sistema de themas vide HALDON, John. Warfare, State and Society in the Byzantine World: 565-1204. Londres: Routledge. 1999, pp. 67-85; NICOLLE, David. Romano-Byzantine Armies 4th-9th Centuries. Londres: Osprey. 1992, pp. 13-17.

${ }^{6}$ HALDON, John. op. cit., p. 73.

${ }^{7}$ Ibidem, p.71.
} 
soldados árabes khuramitas convertidos. Da mesma forma, o Imperador Leão VI (886-912) aumentou ainda mais a proporção da cavalaria em relação à infantaria, tornando os exércitos dos themas mais ofensivos, respondendo à necessidade da nova fase de expansão territorial do Império a partir do século X.

Por outro lado, nas fronteiras do Império, outra situação institucional se desenha. A expansão muçulmana, rápida e avassaladora nos séculos VII e VIII, se estabiliza no século IX. Conseqüentemente, na fronteira entre Bizâncio e Islã, fixada na extremidade oriental da Ásia Menor, cria-se, por uma política empreendida pelos dois lados, uma terra de ninguém. Uma região de guerra, com baixa ocupação humana e atividade econômica. Dominada geograficamente por vales e montanhas, e politicamente por senhores de guerra locais, encastelados em suas fortalezas e exercendo o real poder nessas paragens. Potentados os quais prestavam obediência para o lado que fosse mais conveniente, seja Bizâncio, seja o Califado, mas poucos escrúpulos esses tinham para trocar de lado. Freqüentemente por mais de uma vez.

Para esse contexto específico, Bizâncio criou uma organização específica: as kleisuras. Palavra que significa "vale" ou "passe montanhoso" em grego, fazendo referência aos vales fronteiriços. Esses distritos foram instituídos, aparentemente, no final do século VIII, apesar de serem inspiradas em distritos fronteiriços criados desde, aproximadamente, da década de 630. Originados de tourmas, isto é, de tropas dos Themas, que foram destacadas para as fronteiras. Nesses territórios, os comandantes dessas tropas, os tourmarchas, agora chamados de kleisurarchas, tinham autoridade quase total. ${ }^{9}$

Também é nesse contexto fronteiriço bizantino que encontramos a emblemática figura do akrites. Palavra que vem do grego para o termo "fronteira" ou "extremo", isto é, akra e designa, de uma forma geral, o soldado que protege as fronteiras bizantinas.

\footnotetext{
${ }^{8}$ TREADGOLD. Warren, op.cit., p. 547.

${ }^{9}$ HALDON, John. op. cit., p.78 e pp. 114-115; NICOLLE, David, op.cit., pp. 14.
} 
Como foi observado no valioso trabalho de Agostino Pertusi ${ }^{10}$, fontes do mesmo período diferem em sua descrição de akrites. De forma que, primeiramente, observamos De Cerimoniis do Imperador Constantino Porfirogenito, da primeira metade do século X, que é a primeira referência documental sobre os akrites, onde o autor imperial diz que, ao ir aos extremos do Império, as fronteiras, o Imperador deve dispensar toda a pompa imperial e se acompanhar por 500 akrites escolhidos entre os melhores homens dos Themata fronteiriço pelo Drougario da Bigla, o responsável pela segurança pessoal do Imperador. ${ }^{11}$ Já em Velitatione Bellica, atribuído ao Imperador Nicéforo Focas (963-969), se refere aos akrites tanto como kaminobiglatores, isto é, sentinelas e vigias dos caminhos que dão acesso ao território imperial, quanto trapezitai, isto é, soldados milicianos. Entre outros postos específicos.

Depois de citar essas fontes, Pertusi discorre em qual categoria de mobilização, das que existiam no Império Bizantino do século IX a XI, os akrites se enquadravam. Como Strateoumenoi? Isto é, soldados combatentes, milicianos, que tinham todos os armamentos e todo o sustento pagos pelo governo imperial, segundo o sistema de douleia. Ou como stratiotai? Soldados-camponeses do sistema de strateia. Analisando as fontes escolhidas, autor conclui que:

Os akrites de fato, nos poucos testemunhos que temos, não aprecem mais como stratiotai, mais freqüentemente como strateomenoi, isto é, soldados combatentes, assumindo a douleia ou serviço militar. Esses podiam, muito provavelmente, estar em posse de um bem militar e com os proventos dele prover o seu próprio armamento, mas não deveriam estar necessariamente

${ }^{10}$ PERTUSI, Agostino. Akritai e Ghâzi sulla frontiera orientale di Bisanzio . In: Actes du XVIe. Congrès International des Estudes Byzantines. Bucareste: Academiei Republicii Socialiste România. 1974, pp.237-284.

${ }^{11}$ CONSTATINO PORFIROGENITO. De Cerimoniis. apud PERTUSI, Agostino. op. cit., pp. 240-242.

${ }^{12}$ NICÉFORO FOCAS. Velitatione Bellica. Apud PERTUSI, Agostino. op. cit., pp. 241-245. 
de posse, porque todo armamento e todo sustento deveria prover do estado 13

Conclusão que faz bastante sentido, já que a proteção da fronteira era um trabalho integral. Deveria exigir, tanto do soldado quanto do comandante, atenção exclusiva, tirando assim qualquer possibilidade de disponibilidade desses akrites de trabalhar na própria terra. No entanto, como diz o próprio autor, esses, apesar de não necessariamente terem terras, poderiam tê-las, se fossem trabalhadas por dependentes, familiares ou servos.

No século $X$, observa-se uma mudança expressiva nas fronteiras orientais bizantinas. A expansão territorial vista nesse século amplia as antigas kleisuras que se tornam themas, ou mesmo themas completamente novos são criados dos territórios conquistados. Porém esses novos distritos fronteiriços diferenciavam-se dos antigos pela nomenclatura, os antigos passaram a ser chamados de themas "grandes" (megalon) ou "romanos", enquanto os da fronteira eram chamados simplesmente de "fronteiriços" (akritikon) ou "armênios" (armeniakon), devido ao fato de que a população local na fronteira oriental bizantina era, em grande parte, de etnia armênia. ${ }^{14}$ Já os comandantes desses distritos tinham a mesma função dos Strategos, porém eram considerados "menores" e por vezes chamados de akrites. Assim vemos que assim como o conceito de fronteira, o termo akrites muda expressivamente de significado, não mais nomeando esses soldados, sentinelas e mensageiros que vigiavam as fronteiras do Império mas os próprios comandantes dos distritos limítrofes. Vários manuais militares

\footnotetext{
${ }^{13}$ Gli akriti in effetti, nei pochi testi che li ricordano, non appaiono mais come stratiôtai, mais piuttosto come strateuómenoi, cioè como soldati combattenti, s'assumono la douleia o servizio militare. Essi possono, molto probabilmente, essere in possesso di um bene militare e com i proventi di esso provvedere al proprio armamento, ma non debbono esserne necessariamente in possesso, perchè al loro armamento e al loro sostentamento puo o deve provvedere lo stato. In: PERTUSI, Agostino, op. cit., p. 244.

${ }^{14}$ HALDON, John, op. cit., p. 84.
} 
atestam essa mudança, porém um dos mais ricos em informações sobre esses "novos akrites" é o Strategikon de Cecaumenos.

Strategikon é um livro de conselhos da segunda metade do século XI e, ao contrário dos outros Strategikon, como o de Mauricio, do século VII, e do Imperador Leão VI, do século X, o de Cecaumenos não se limitou a enumerar e analisar táticas e estratégias de guerra, técnicas de cerco e castramento, assuntos militares em geral, como também trata de uma enorme gama de assuntos. Política, vida familiar, economia doméstica, religião e moral. Porém o autor não se aprofunda demais em detalhes técnicos militares, pois, como disse o próprio Cecaumenos, autores antigos já tinham feito. ${ }^{15}$

Cecaumenos, o autor, era parte da aristocracia militar surgida a partir da citada expansão do mundo bizantino, observado a partir do século $\mathrm{X}$, e, como havia de se esperar, seguiu uma carreira no exército imperial. Esta deve ter se iniciado na década de 1030, pois participou de uma campanha militar contra a revolta do líder búlgaro Pedro Delian em 1041. ${ }^{16}$ Cecaumenos posteriormente esteve em Constantinopla na revolta popular que destituiu Miguel V, em 1042, ${ }^{17}$ e ocupou um cargo, provavelmente de Strategos, não sabemos quando, na Thema da Tessália. ${ }^{18} \mathrm{Da}$ mesma forma podemos saber a época aproximada em que ele escreveu o Strategikon, pois menciona o Imperador Miguel VII (1071-1078) como sendo o ocupante atual do trono imperial. ${ }^{19}$ Portanto, se levarmos em consideração a experiência bélica do autor na Bulgária, em 1041, mesmo que ainda fosse muito jovem, estivesse com mais ou menos 20 anos, ele deveria ter no mínimo 50 anos quando escreveu esta obra, mas provavelmente era bem mais velho. Então consideramos o autor

\footnotetext{
${ }^{15}$ CECAUMENO. Strategikon: Consejos de un Aristócrata Bizantino. Introdução, tradução e notas de Juan Signes Cordoñer. Madri: Alianza Editorial. 2000, VI, 3.

${ }^{16}$ CECAUMENO, XV, 8, V.

${ }^{17}$ CECAUMENO, XI, 26, XV, 11-14.

${ }^{18}$ CECAUMENO, XI, 30.

${ }^{19}$ CECAUMENO, XII, $1, \mathrm{X}$.
} 
sendo um homem de idade bastante avançada, se levarmos em consideração a baixa expectativa de vida em sociedades préindustriais.

É importante aqui apontar que a época na qual Cecaumenos escreve seu Strategikon, a década de 1070, é marcada pela crise dessa estrutura de organização governamental bizantina. Após a morte do Imperador-guerreiro Basílio II, em 1025, o Império Bizantino foi posto em mãos, em primeiro lugar, de regentes em nome dos últimos representantes da Dinastia Macedônia, sem interesses pela governança e sem descendentes. Esses regentes provinham, em sua maioria, da elite burocrática de Constantinopla, os quais sobem ao poder e se destituem continuadamente. Situação agravada, sobretudo, após a morte do último membro da Dinastia, a Imperatriz Teodora, em 1056. Contudo, apesar da fragilidade política, que nasce após a morte de Basílio II, o Império se manteve forte devido ao sistema themático ainda mantido. Essa situação começa a mudar quando a aristocracia civil, empossada da púrpura imperial, decidiu enfraquecer seus adversários diretos, a aristocracia rural, pela sua base, desmontando o sistema de mobilização dos themas. Porém não podemos pensar que a aristocracia militar e a burocrática eram blocos politicamente coesos, havia sim dissensões e rivalidades dentro desses grupos e muitas, assim como algumas alianças entre elementos de diferentes grupos, porém no século XI começou a haver uma crescente polarização desses dois estratos sócio-políticos de elite.

Podemos observar alguns casos de desmobilização de soldados anteriores a esse período, mas suas razões foram práticas. A expansão territorial que marcou o século $\mathrm{X}$ fez com que alguns dos Themas mais distantes da fronteira expandida ficassem seguros de ataques estrangeiros e o resultado disso foi que os soldados desses distritos ficaram tanto tempo inativos que perderam sua prática. Assim se tornaram inúteis e caros, pois ainda tinham que receber o pago. A solução do governo imperial a 
esse problema foi a retirada dos soldados do sistema de strateia, os quais passaram a pagar impostos em substituição ao serviço militar. No entanto, o esquema se manteve no que se referia aos themas mais fronteiriços, onde se concentravam a maioria dos soldados, assim como os mais experientes. Essa situação vai mudar no reinado de Constantino IX Monomachos (1042-1055), imperador que dispensou, mais por motivos econômicos do que políticos ou militares, todos os soldados do thema dos armênios, os themas fronteiriços, substituindo-os por tropas mercenárias estrangeiras e protetorados fronteiriços. ${ }^{20}$ No fim, essa iniciativa se tornou catastrófica, pois o controle sobre os mercenários era tênue, assim como sua fidelidade, e o mesmo aconteceu com os protetorados. O resultado foi que o território imperial se abriu para invasões e os Turcos Sedjulcidas, os novos "protetores" do Califado Abássida, se aproveitaram disso, implicando assim na famosa derrota bizantina para os turcos em Manzikert, na Armênia, em 1071, na qual o que restava do exército bizantino foi destruído e dispersado. Desse modo, o território imperial foi rapidamente ocupado por hordas turcas, com exceção às principais cidades onde os governadores locais, com suas tropas, se achavam fortes suficientes para aspirarem ao trono imperial, em contraste a um governo decapitado, pois o Imperador Romano IV Diógenes havia sido capturado em batalha. É nesse contexto caótico, pósderrota, que Cecaumenos escreve seu Srategikon. Mas, observando essas mudanças, nos perguntamos: qual a razão de Cecaumenos escrever seus conselhos ancorados num mundo que estava se desmanchando? A obra dele nos dá alguns indícios. Vemos, principalmente nos conselhos dirigidos ao Imperador, onde Cecaumenos adverte-o a não fazer coisas que os últimos Imperadores de fato estavam fazendo. À exemplo do conselho para que o Imperador não se esqueça dos soldados ao distribuir dignidades ${ }^{21}$, não deixar de pagar o soldo ${ }^{22}$ e não abrir mão do

\footnotetext{
${ }^{20}$ TREADGOLD, Warren, op.cit., pp. 595-596.

${ }^{21}$ CECAUMENO, XV, 7.
} 
serviço deles em troca de dinheiro. ${ }^{23}$ Desse modo, talvez Cecaumenos ainda tivesse esperança de que algum imperador surgisse, restaurasse a boa ordem no Império e, dessa forma, voltasse a gloria da época de Basílio II, quem Cecaumenos cita muitas vezes, elogiosamente, em seus conselhos. Da mesma forma é evidente, nessa inadequação dos conselhos do autor com o contexto em que escreve, o típico fenômeno histórico do observador que descreve uma situação a qual não compreende inteiramente. Talvez Cecaumenos, um indivíduo já de certa idade, que via o mundo a sua volta sofrer grandes mudanças as quais não compreendia ou não queria compreender, por estar muito ligado ao mundo que está quase desaparecendo. Enfim, esta é ainda uma questão em aberto, porém, através desse anacronismo, podemos situar a imagem de akrites passada por Cecaumenos para um período de entre, aproximadamente, 930 e 1050. Datas essas que limitam o início da grande expansão oriental bizantina no reinado de Romano Lekapeno(920-944) e a desmobilização dos themas fronteiriços por Constantino IX Monomachos.

A primeira referência aos akrites que achamos no Strategikon é uma censura, onde Cecaumenos acusa-os de serem responsáveis pela invasão dos petchenegos, um povo eslavo, para dentro do território imperial. A razão disso, segundo o autor, é a indolência desses akrites que, enquanto adulam o Imperador, descuidam de sua principal função: a proteção das fronteiras. Por isso o autor recomenda que esses akrites fossem não só censurados publicamente, como também punidos. ${ }^{24}$ Desse modo, através da censura a figura dos akrites, podemos observar a função crucial, para Cecaumenos, desses de serem os principais responsáveis pela integridade da fronteira, e, por conseguinte, do próprio território imperial. No entanto, com a transformação das

\footnotetext{
${ }^{22}$ CECAUMENO, XV, 9.

${ }^{23}$ CECAUMENO, XV, 17, I.

${ }^{24}$ CECAUMENO, VI, 26.
} 
antigas kleisuras para themas, as funções dos akrites e dos strategos se confundem, já que os distritos do interior e da fronteira são, aparentemente, de igual constituição e organização. Contudo, a pequena obra de Cecaumenos nos dá interessantes indícios para construir uma diferenciação.

Primeiramente, ao observarmos os conselhos do Strategikon, podemos classificá-los como militares, aqueles que têm uma proposta de aconselhar o leitor para organizações de campanhas, castramento, cerco, batalhas, manutenção de soldados etc, administrativos ou econômicos, os conselhos sobre administração e organização de desde propriedades privadas até de themas que poderiam estar sob a responsabilidade dos leitores, os políticos e os sociais, que se referem ao comportamento individual ou coletivo. E, ao fazer o paralelo entre os conselhos dirigidos aos strategos e aos akrites e elencá-los segundo o modelo proposto, observamos claramente as diferenças entre esses dois cargos. Apesar de que, em ambos os grupos de conselhos, haja uma predominância de admoestações militares, trinta de quarenta, no caso dos conselhos aos strategos, e dezessete de vinte e um, no caso dos dirigidos aos akrites, podemos ver as diferenças na minoria. Se os conselhos não-militares aos Strategos, dez no total, são sobre a legislação e administração dos themas, abusos de recolhedores de impostos, o porte $\mathrm{e}$ comportamento de um aristocrata, os poucos conselhos de caráter "não-militar aos akrites, quatro no total, se distinguem como políticos, porém impregnados de um fundo militar. Um deles aconselha não confiar em bárbaros que se aproximam de sua fortaleza com propósitos pacíficos e, por exemplo, fazer mercado, pois, uma vez dentro dela, aproveitam a chance e tentam tomála. ${ }^{25}$ Já os outros três conselhos tratam da relação dos akrites com os toparcas vizinhos. Os toparcas são aqueles potentados independentes ou semi-independentes que vicejavam, numerosos, nas fronteiras entre Bizâncio e o Califado. Em relação a esses,

${ }^{25}$ CECAUMENO, VII, 20. 
Cecaumenos recomenda aos akrites restrição total, não devem ser confiados de forma alguma. Contudo, se os toparcas se mostrarem pacíficos, o autor sugere que os deixem em paz, sem, no entanto, tirar os olhos de suas forças e de seus territórios. Se, por outro lado, o toparca se mostra agressivo e belicoso, Cecaumenos recomenda, seguindo as mais tradicionais modi operandii bizantino, que o akrites deve adular-lo, com cartas e presentes, o maior tempo possível, enquanto junta forças e, por fim, atacar o seu território de surpresa. Agindo desse modo, o autor garante o sucesso da empreitada, que daria aos akrites honra, respeito, reconhecimento pessoal e recompensas do próprio Imperador. ${ }^{26}$

É interessante apontar que Cecaumenos faz também, no Strategikon, uma pequena série de conselhos aos toparcas, onde recomenda o mesmo tipo de cuidado em relação aos akrites. Nesse conselho, Cecaumenos diz o seguinte sobre eles: "Así, cuando te descuides, atacará tu ciudad o tu território y se apodera de él. Es preciso que vigiles a los amigos más que a los inimigos" 27 , fazendo uma clara referência aos conselhos que ele mesmo dá aos akrites.

Observando, desse modo, pela natureza dos conselhos de Cecaumenos, o caráter predominantemente militar desse "novo" akrites, vemos que, diferentemente do strategos, que tinha, além de sua função militar, a incumbência de ser o administrador e legislador dos assuntos cotidianos e econômicos locais, os comandantes dos distritos fronteiriços não tinham essa natureza "governativa" dos strategos, ou ela não era importante. Porque não podemos considerar que a fronteira bizantina era um vazio demográfico e econômico, havia sim vilas e até mesmo cidades de relativa importância política e econômica nessas regiões, e provavelmente os akrites eram a autoridade administrativa e jurídica nesses lugares. Provavelmente eles habitavam nessas vilas e cidades. Contudo, a proteção das fronteiras deveria ser

\footnotetext{
${ }^{26}$ CECAUMENO, VII, 6 e 7.

${ }^{27}$ CECAUMENO, XVI, 9.
} 
incomensuravelmente mais importante que a administração desses centros populacionais que, a qualquer momento, poderiam ser invadidos, saqueados ou cair em mãos inimigas. Nesse sentido, da importância da integridade e segurança da fronteira, adicionando a fragilidade da autoridade local nesses territórios, quem quer que ela seja, compreendemos a ausência de conselhos administrativos ou econômicos nas admoestações aos akrites.

Dentre várias táticas e estratégias apontadas por Cecaumenos, de cercar e defender fortalezas, estratégias de ataque e defesas em batalhas etc, podemos apontar algumas que representam as especificidades do guerrear na fronteira. Já no primeiro dos conselhos aos akrites, o autor recomenda que eles, ao tratar da indisciplina de seus soldados, o façam com cuidado, punindo alguns desvios e virando os olhos para outros, pois um tratamento por demais duro pode decorrer em revoltas de soldados e uma mudança de fidelidade desses para os inimigos, comprometendo, desse modo, a segurança desses distritos de fronteira e, por conseqüência, do Império. Demonstrando, mais uma vez, a fragilidade da autoridade local dos akrites. ${ }^{28}$

Outro conselho interessante é sobre como o akrites deve agir em caso de invasões bárbaras, se no caso de elas serem pequenas e ele consiga sobrepor a invasão em força, ele deveria fazer frente a ela. Contudo, se forem invasões de grande porte, os akrites deveriam tão somente segui-las, atacando tropas e homens que se destacassem da força principal. Infringindo o medo e o temor nas forças invasoras, fazendo que elas se movam juntas e não se separem para fazer pequenos saques e ataques ${ }^{29}$. Por sua vez, os akrites, quando forem atacar territórios estrangeiros, devem evitar tomar o mesmo caminho na volta, ainda mais se o caminho for um vale, numerosos nas fronteiras orientais do Império. No entanto, se não houver outro caminho, o akrites

\footnotetext{
${ }^{28}$ CECAUMENO, VII, 1.

${ }^{29}$ CECAUMENO, VII, 2.
} 
deveria pôr sentinelas em lugares estratégicos, para que garantissem uma volta para casa segura e livre de emboscadas. ${ }^{3}$

Apesar da ausência de conselhos referentes à administração e economia de cidades, vemos muitos conselhos e exemplos históricos de Cecaumenos em relação à defesa de fortaleza, os kastra, ${ }^{31}$ o que é compreensível, uma vez que essas fortalezas tinham função análoga aos famosos castelos do ocidente medieval. Onde se organizavam as defesas do território, onde a população local podia achar proteção em caso de invasões, era o centro econômico e era onde a autoridade imperial, encarnada pelos akrites ou por enviados esporádicos, como recolhedores de impostos, agia. Portanto, manter esses kastra era sinônimo de manter autoridade nas fronteiras e, como vimos a dificuldade de fazer isso, compreendemos a sua importância.

A partir dessas observações dos conselhos de Cecaumenos aos akrites, podemos ver que há algo de heróico na função deles. A tarefa de proteger, naquelas paragens semi-bárbaras, afastadas do brilho da capital imperial, Constantinopla, o ideal de Romania, construído ao longo dos séculos por escritores e ideólogos bizantinos, faziam desses akrites algo mais do que simples tentáculos de um poder central distante, muito distante. Por isso, é mais do que natural que esses chefes-de-guerra, semiindependentes, que quase tão somente de forma nominal eram subordinados a esse longínquo poder constantinopolitano, tenham se tornado fonte de inspiração de uma das mais "vanguardistas", se levar em consideração o conservadorismo bizantino, expressão cultural que o Império já viu: o surgimento de uma literatura épica, que nasce nesses ambientes fronteiriços e têm os akrites como heróis, e num segundo momento, nos finais do século XI e início do XII, tais canções épicas ganharam uma forma escrita e

\footnotetext{
${ }^{30}$ CECAUMENO, VII, 8 e 9.

${ }^{31}$ CECAUMENO, VII, 10-20
} 
sintetizada na figura de um só personagem arquetípico, Basílio Digenis Akrites. ${ }^{32}$

\section{BIBLIOGRAFIA}

ARCE, Javier. La Frontera Del Império Persa: Constâncio II y Heráclio. Eryhteia: numero 8/1, Madrid: Asociación HispanoHelenica. 1987.

CASTILlO, Miguel. Poesia Heróica Bizantina: Epopeya de Digenis Akritas, cantares de Armuris y Andronico. Santiago: Centro de Estudos Neohelenicos e Bizantinos. 1994.

CECAUMENO. Strategikon: Consejos de un Aristócrata Bizantino. Introdução, tradução e notas de Juan Signes Cordoñer. Madri: Alianza Editorial. 2000.

BEATON, Roderick. The Medieval Greek Romance: 2nd Edition. Londres: Routledge.1996.

HALDON, John. Warfare, State and Society in the Byzantine World: 565-1204. Londres: Routledge. 1999.

KAZHDAN. A. P. \& EPSTEIN, Ann Wharton. Change in Byzantine Culture in the Eleventh and Twelfht Centuries. Berkeley: University of California Press. 1985.

NICOLLE, David. Romano-Byzantine Armies 4th-9th Centuries. Londres: Osprey. 1992

PATlAGEAN,E. et al. Historia de Bizâncio. Critica: Barcelona. 2001.

PERTUSI, Agostino. Akritai e Ghâzi sulla frontiera orientale di Bisanzio . In: Actes du XVIe. Congrès International des Estudes

32 Sobre o surgimento da épica bizantina de fronteira vide BEATON, Roderick. The Medieval Greek Romance: 2nd Edition. Londres: Routledge, 1996, pp. 30-51. \& CASTILlO, Miguel. Poesia Heróica Bizantina: Epopeya de Digenis Akritas, cantares de Armuris y Andronico. Santiago: Centro de Estudos Neohelenicos e Bizantinos, 1994, pp. 41-112 
Byzantines. Bucareste: Academiei Republicii Socialiste România. 1974.

TREADGOLD. Warren. A History of the Byzantine State and Society. Stanford, California: Stanford University Press, 1997, pp. 287-306. 